\title{
Turbulent Heat Transfer and Pressure Loss in a Square-Duct Heat Exchanger with Inclined-Baffle Inserts
}

\section{Narin Koolnapadol ${ }^{1}$, Panuwat Hoonpong ${ }^{2}$, Sompol Skullong ${ }^{3, a, b, *}$, Pongsak Kammul ${ }^{4}$, and Pongjet Promvonge ${ }^{4}$}

1 Department of Automotive Mechanical Engineering, Faculty of Industrial Technology, Rajabhat Rajanagarindra University, Chachoengsao 24000, Thailand

2 Department of Mechanical Technology, Faculty of Industrial Technology, Thepsatri Rajabhat University, 321 Naraimaharat Road, Talaychubsorn, Lopburi 15000, Thailand.

3 Department of Mechanical Engineering, Faculty of Engineering at Sriracha, Kasetsart University Sriracha Campus, 199 M.6, Sukhumvit Rd., Sriracha, Chonburi 20230, Thailand

4 Department of Mechanical Engineering, Faculty of Engineering, King Mongkut's Institute of Technology Ladkrabang, Bangkok 10520, Thailand

E-mail: asfengsps@src.ku.ac.th, bsompol@eng.src.ku.ac.th (Corresponding author)

\begin{abstract}
Thermal and friction loss characteristics in a square-duct heat exchanger fitted with inclinedbaffles are experimentally examined. Air as the test fluid enters the test duct having a uniform surface heatflux. The baffles are placed repeatedly on both sides of a rectangular centre-cleared tape/frame before diagonally inserting the baffled frame into the test duct to produce longitudinal vortex flows through the test section. Effects of five different relative baffle height or flow blockage ratios $(b / H=\mathrm{BR}=0.1,0.2,0.3$, 0.4 and 0.5 ) on heat transfer, pressure loss and thermal performance in the square duct are investigated for Reynolds number ranging from 4100 to 25,600 . The relative baffle pitch or pitch ratio $(P / H=P R)$ and baffle attack angle $(\alpha)$ are fixed at 3.0 and $30^{\circ}$, respectively. The experimental results reveal that the heat transfer and pressure drop in the form of respective Nusselt number $(\mathrm{Nu})$ and friction factor $(f)$ from using the baffle tend to increase with the rise of Reynolds number (Re) and BR. The maximum enhancement in $\mathrm{Nu}$ and $f$ has been found to be 4.61 and 63.67 times above the smooth duct, respectively. The thermal enhancement factor $(\eta)$ is maximum at $\mathrm{BR}=0.3$.
\end{abstract}

Keywords: Inclined baffle, square duct, thermal performance, Reynolds number, vortex generator.

ENGINEERING JOURNAL Volume 21 Issue 7

Received 1 September 2017

Accepted 18 October 2017

Published 29 December 2017

Online at http://www.engj.org/

DOI:10.4186/ej.2017.21.7.485 


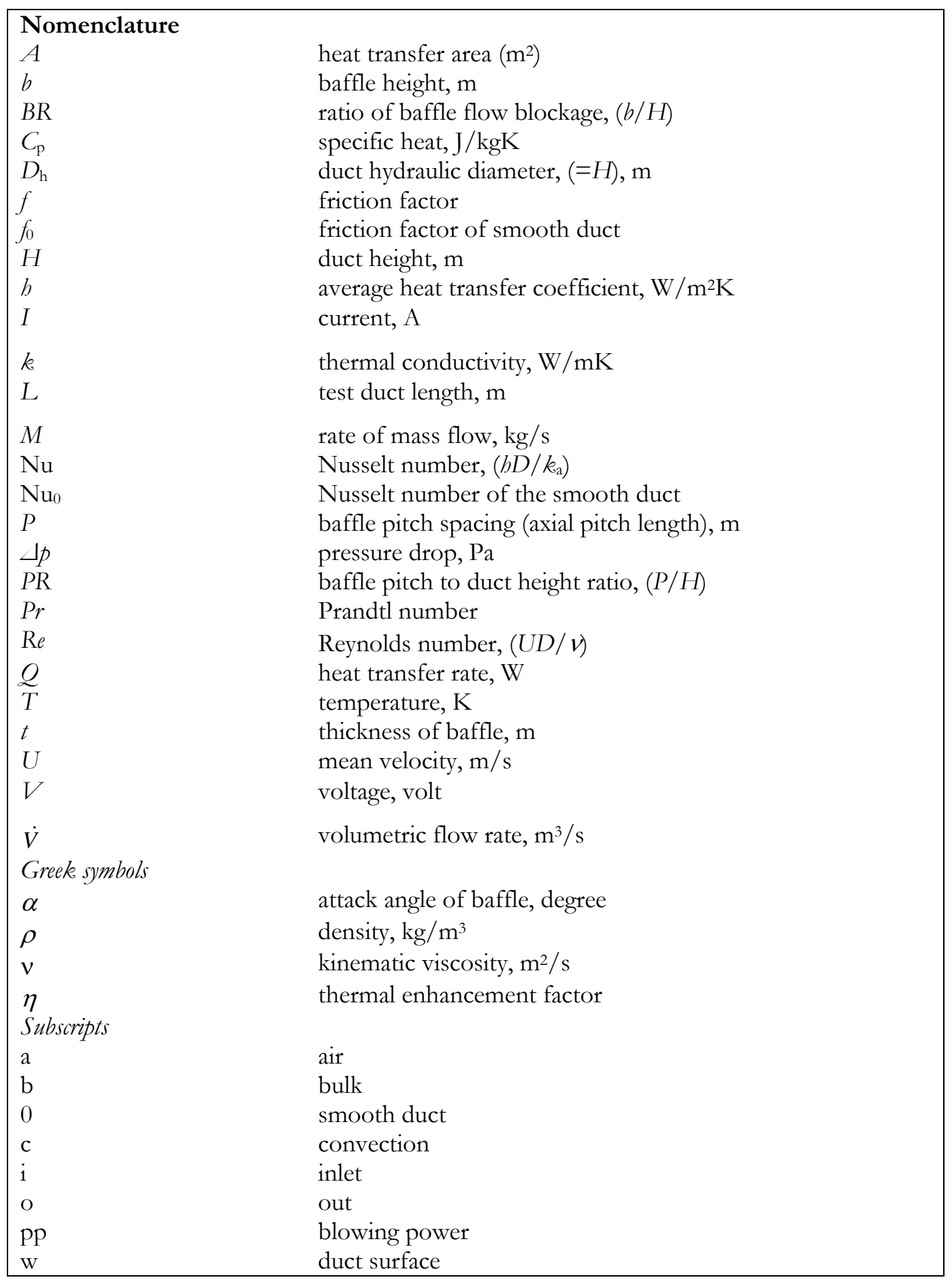

\section{Introduction}

Vortex/swirl flows have been widely applied in heating/cooling systems in order to increase thermal performance of heat exchangers used in industrial applications such as, steam generation, chemical processing, electric power generation, etc. Vortex flow devices such as rib/baffle, groove, coiled-wire, twisted tape, winglet etc are extensively applied for heat transfer augmentation (HTA) in heating or cooling passages, for example, vortex tube [1], solar air heater [2-4] and heat exchanger systems [5-7]. The HTA by baffles relies on induced vortex (or high swirl) in the flow of fluid. The vortex generators (VGs) are inserted into the flow field to provide an interruption of boundary layer development and to cause enhancement of the rate of heat transfer by increasing turbulence intensity. Several researchers have reported the effects of tube insert with swirl or vortex flow devices on the HTA, pressure loss and thermal 
performance. Sivashanmugam and Suresh [8] studied the turbulent flow and thermal characteristics in a round tube inserted with full-length helical screw elements having different twist ratios with increasing and decreasing order of twist ratios. Promvonge and Eiamsa-ard [9] experimentally examined the flow friction and thermal characteristics in a heat exchanger tube with conical-nozzle inserts. They pointed out that the conical-nozzle turbulator provides the heat transfer rate higher than the plain tube alone at a range of 236 to $344 \%$. Kreith and Margolis [10] reported that the increase in heat transfer can be made by vortex flow in a heat exchanger tube using fluid tangential injection at several locations along the tube. Promvonge and Eiamsa-ard [11] experimentally investigated heat transfer characteristics in a uniform heat-fluxed circular tube fitted with free-spacing snail entry and conical-nozzle turbulators. Therefore, significant improvement of heat transfer as well as friction loss along the tube wall was reported. Promvonge et al. [12] studied thermal characteristics in a helical-ribbed tube fitted with double twisted-tapes. They found that the heat transfer enhanced by the inserted ribbed-tube was, respectively, higher than that by the ribbed tube alone and the smooth tube at about $4-75 \%$ and $150-320 \%$. Chang et al. [13] examined thermal behaviors in a circular tube contained with twisted tapes having the serrations in the form of the square-sectioned ribs on two tape edges and twist ratios of 1.56, 1.88, 2.81 and $\infty$ where the rib pitch and height are identical. Eiamsa-ard et al. [14] investigated thermal characteristics in a tube with two-typed regularly spaced twisted tapes: full-length typical twisted tape with different twist ratios and twisted tapes with various free space ratios $(\mathrm{S}=1.0,2.0$, and 3.0). For compound swirl/vortex generators, Promvonge and Eiamsa-ard [15-17] reported thermal and flow friction characteristics in a uniform heat-fluxed tube fitted with conical-nozzle, conical-ring or V-nozzle in common with a snail-type swirl generator (decaying swirl) and concluded that for the compound devices, the heat transfer rate is increased at about $20-50 \%$ higher than the single use of an enhancement device but also friction loss is substantially increased.

The use of ribs/baffles creating the high strength of vortex flow leads to a considerable increase in heat transfer rate in channels/ducts. Ko and Anand [18] studied experimentally the use of porous baffles in turbulent channel flow to enhance the heat transfer and found that the porous baffles provided thermal behaviors as good as the solid baffles. Berner et al. [19] investigated laminar flow friction and thermal behaviors in a channel with staggered transverse baffles placed on two principal walls and suggested that free of vortex shedding occurred at a Reynolds number below 600. Gupta et al. [20] reported local heat transfer profiles in a square duct fitted with continuous, profiled and V-broken ribs. They showed that the V-broken ribs give higher heat transfer than the continuous and profiled ribs. Experimental and numerical studies on thermal behaviors in a square duct inserted with $30^{\circ}$ angle-finned tapes were conducted by Promvonge et al. [21, 22] who suggested that the tape with smallest fin pitch ratio $(\mathrm{PR}=1)$ provides the highest Nusselt number, friction factor and the thermal enhancement factor.

Most investigations mentioned above have emphasized on thermal behaviors for thin fins/ribs (called "baffle") mounted on the duct wall and the baffles mounted on the typical (solid) tape with diagonal insert. The study on turbulent flows through angled baffles placed on a rectangular centre-cleared tape/frame (perforated tape) has never been found. This type of baffled-tape pattern is considered to be very useful for pressure loss reduction in the thermal systems. Therefore, the key objective in the current work is to propose measured data available on this type of inclined-baffles mounted diagonally. The experiment is conducted using air as the working fluid for five different baffle heights for turbulent flows ranging from $\operatorname{Re}=4100$ to 25,600 .

\section{Experimental Setup and Test Procedure}

\subsection{Details of Inclined Baffle}

The schematic view of inclined baffles chosen for the present study is shown in Fig. 1. Aluminum strips with $0.5 \mathrm{~mm}$ thickness $(t)$ were used to form the baffles while an aluminum sheet with dimensions of 0.5 $\mathrm{mm} \times 1000 \mathrm{~mm} \times 63.6 \mathrm{~mm}$ (thickness, $\delta \times$ length, $L \times$ width, $W_{\mathrm{d}}$ ), was employed as the supporting frame or perforated tape by centrally cut to form the center-cleared tape. The tape width (w) is $0.2 H$ throughout (see Fig. 1). The heights (b) of the baffles were set to 4.5, 9.0, 13.5, 18.0 and $22.5 \mathrm{~mm}$, equivalent to five relative baffles or flow blockage ratios, $b / H=0.1,0.2,0.3,0.4$ and 0.5 , respectively, and were placed on the tape edges at the distance of three-fold duct height, $\mathrm{P} / \mathrm{H}=3$ and at two attack angles $(\alpha)$ of $60^{\circ}$ and $45^{\circ}$. The range of baffle parameters and test conditions is given in Table 1. 
Table 1. Details on baffle geometry and test conditions.

\begin{tabular}{ll}
\hline Working fluid & air \\
Reynolds number, Re & 4100 to 25,600 \\
Duct height $=$ Duct width, $H$ & $45 \mathrm{~mm}$ \\
Diagonal width, $W_{\mathrm{d}}=\sqrt{ } 2 \cdot H$ & $63.6 \mathrm{~mm}$ \\
Hydraulic diameter, $D_{\mathrm{h}}$ & $45 \mathrm{~mm}$ \\
Test section length, $L$ & $1000 \mathrm{~mm}$ \\
Baffle attack angle, $\alpha$ & $30^{\circ}$ (fixed) \\
Blockage ratio, BR & $0.1,0.2,0.3,0.4,0.5$ \\
Pitch ratio, PR & 3 (fixed) \\
Baffle thickness, $t$ & $0.5 \mathrm{~mm}$ \\
Tape length = Test section length, $L$ & $1000 \mathrm{~mm}$ \\
Tape thickness, $\delta$ & $0.5 \mathrm{~mm}$ \\
\hline
\end{tabular}

\subsection{Experimental Procedure}

The schematic representation of experimental facility and test section of square-duct heat exchanger is shown in Fig. 2. The key components in the experimental setup were a high-pressure blower, aluminum square-duct, electric heater, orifice plate, circular pipe, settling tank, AC power supply, inclined manometer, ammeter, voltmeter, thermocouples. The $3 \mathrm{~mm}$ thick aluminum sheets were formed to be the test duct having a cross section of $45 \mathrm{~mm} \times 45 \mathrm{~mm}$ (hydraulic diameter, $D_{\mathrm{h}}=45 \mathrm{~mm}$ ) and $1000 \mathrm{~mm}$ in length $(L)$. A uniform heat flux of $3000 \mathrm{~W} / \mathrm{m}^{2}$ (maximum) was applied to all the duct walls and was maintained using AC power supply (variable transformer). Air at room temperature $\left(25^{\circ} \mathrm{C}\right)$ entered the system by a high-pressure blower. A high-pressure blower was used to supply the room air to system and connected to a settling tank by a round pipe where an orifice plate was placed in this pipeline. Ten values of volumetric flow rates were maintained to cover the entire range of Reynolds number (4100-25,600). 28 K-type thermocouples were employed by attaching them on the outer duct walls to measure the temperature variations along the test duct. Also, to measure the inlet air temperature and the outlet air temperature of the test duct, two thermocouples of K-type were positioned at the entrance and exit. A data acquisition system (Fluke 2680A) was used to receive the signal from the mentioned thermocouples and was recorded by a laptop. More details of the method and uncertainty analysis are similar as reported in earlier paper [23].

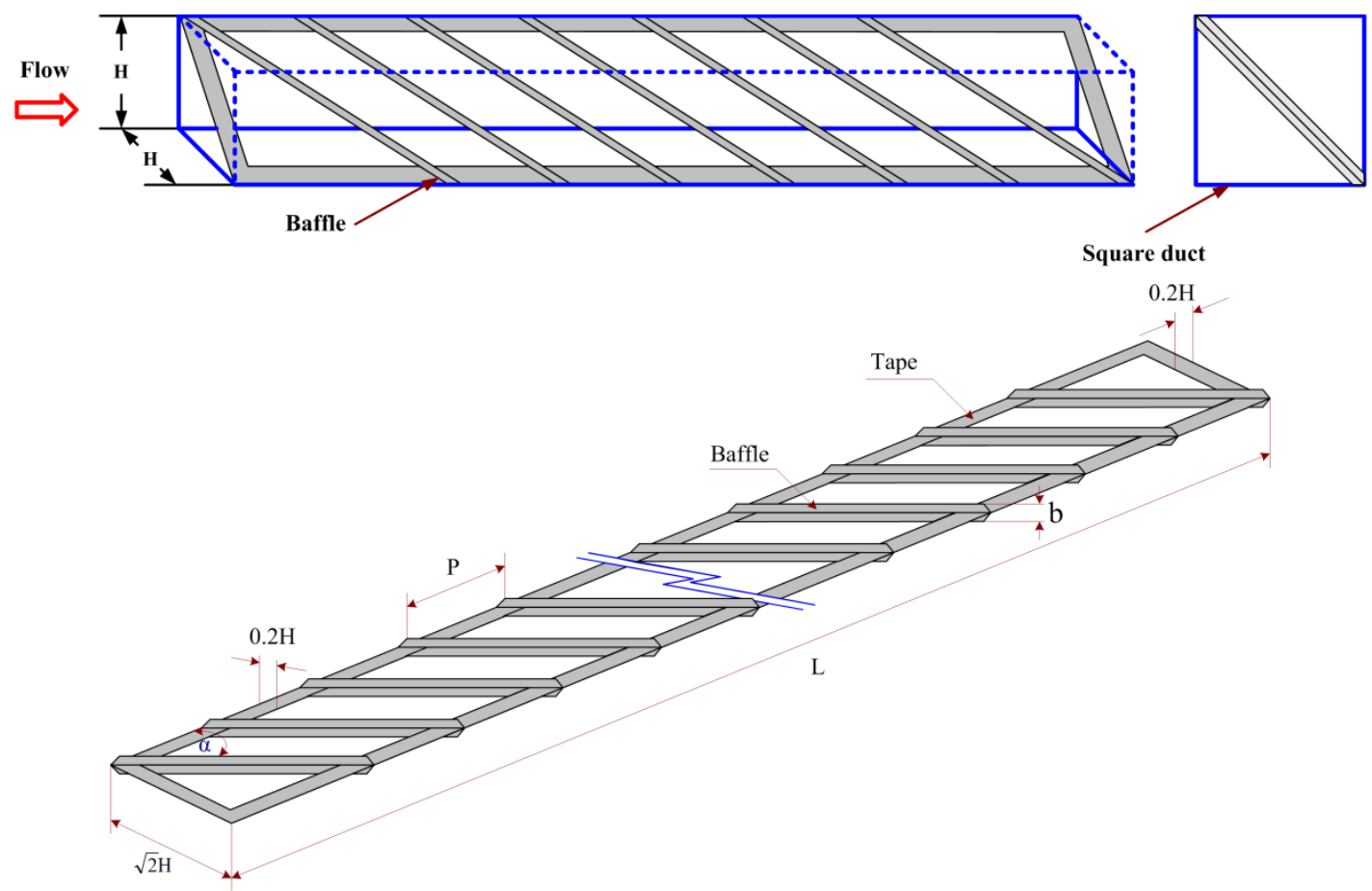

Fig. 1. Details of test duct along with inclined baffles. 


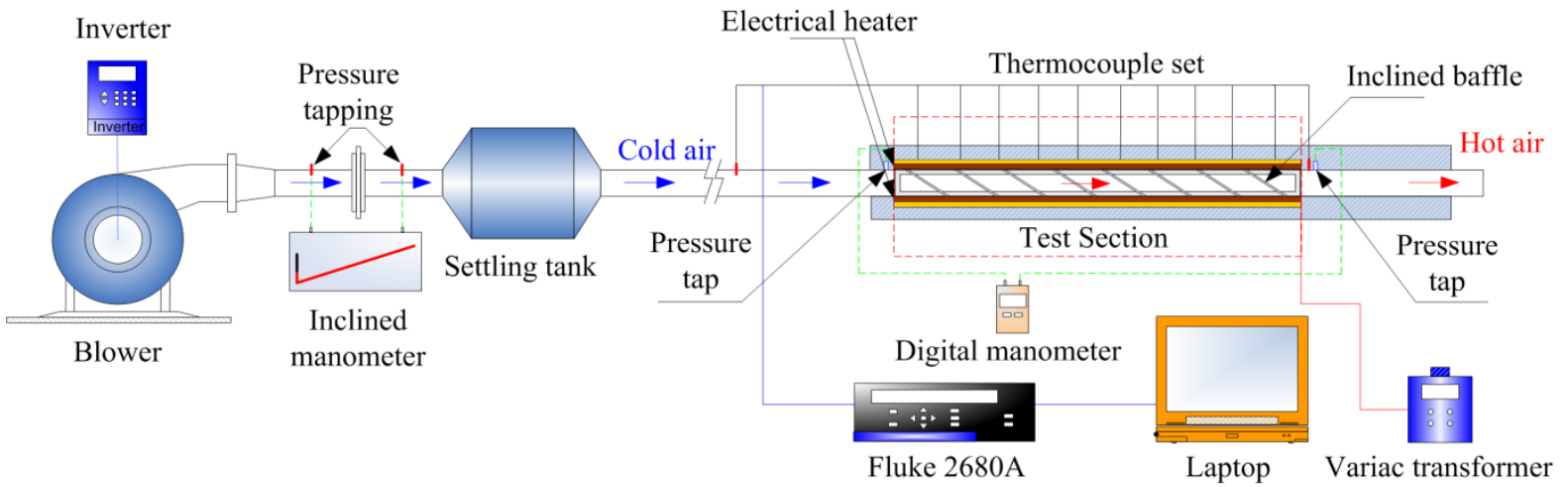

Fig. 2. Schematic of experimental setup.

\section{Data Analysis}

In the current study, air as the test fluid is flowed into a constant heat-fluxed square-duct heat exchanger. Due to steady-state condition, the rate of heat transfer is set equally to the convection heat loss in the duct. By uniformly adding heat to fluid $\left(Q_{\text {air }}\right)$, the average heat transfer coefficient is evaluated through the temperature difference of tube wall and fluid $\left(T_{\mathrm{w}}-T_{\mathrm{b}}\right)$ by the equations below:

$$
\begin{gathered}
Q_{\mathrm{a}}=Q_{\mathrm{c}}=M \cdot C_{\mathrm{p}} \cdot\left(T_{\mathrm{o}}-T_{\mathrm{i}}\right)=V I \\
h=Q_{\mathrm{c}} /\left(A \cdot\left(\tilde{T}_{\mathrm{w}}-T_{\mathrm{b}}\right)\right)
\end{gathered}
$$

where,

$$
T_{\mathrm{b}}=\left(T_{\mathrm{o}}+T_{\mathrm{i}}\right) / 2
$$

and

$$
\tilde{T}_{\mathrm{w}}=\sum T_{\mathrm{w}} / 28
$$

in which $A, T_{\mathrm{b}}$ and $\tilde{T}_{\mathrm{w}}$ are the heat transfer surface area, bulk fluid temperature in the test duct and average wall temperature along the test duct, respectively. Then, average Nusselt number $(\mathrm{Nu})$ is calculated by

$$
\mathrm{Nu}=\left(h \cdot D_{h}\right) / k
$$

The hydraulic diameter $\left(D_{\mathrm{h}}\right)$ of the duct is used for finding Reynolds number $(\mathrm{Re})$ as given by

$$
\operatorname{Re}=U \cdot D_{h} / v
$$

Also, pressure loss displayed in the form of friction factor $(f)$ is written by:

$$
f=\frac{2}{\left(L / D_{h}\right)} \frac{\Delta p}{\rho U^{2}}
$$

Thermal performance of the system shown in terms of thermal enhancement factor, $\eta$, defined as the ratio of $\mathrm{Nu}$ of baffle insert, $h$ to $\mathrm{Nu}$ of a flat duct alone, $h_{0}$, at an equal blowing power [24] is written as

$$
\eta=\left.\frac{\mathrm{Nu}}{\mathrm{Nu}_{0}}\right|_{\mathrm{pp}}=\left(\frac{\mathrm{Nu}}{\mathrm{Nu}_{0}}\right)\left(\frac{f_{0}}{f}\right)^{1 / 3}
$$




\section{Results and Discussion}

\subsection{Verification of Smooth Square-Duct}

The current experimental results of $\mathrm{Nu}$ and $f$ from the present flat duct are initially verified by comparing them with those obtained from the correlations of Gnielinski and Petukhov [25] for turbulent duct flow.

Correlation of Gnielinski,

$$
\mathrm{Nu}=\frac{(f / 8)(\operatorname{Re}-1000) \operatorname{Pr}}{1+12.7(f / 8)^{0.5}\left(\operatorname{Pr}^{2 / 3}-1\right)}
$$

Correlation of Petukhov,

$$
f=(0.79 \ln \operatorname{Re}-1.64)^{-2}
$$

The experimental and correlation values of $\mathrm{Nu}$ and $f$ are, respectively, plotted and shown in Fig. 3a and b. In the figure, the average deviations for $\mathrm{Nu}$ and $f$ are seen to be about $5.1 \%$ and $5.6 \%$, respectively which shows an excellent agreement between both the results.

\subsection{Heat Transfer Results}

An experimental study has been carried out to study the augmentation of heat transfer by using $30^{\circ}$ diagonally inclined baffles inserted in a square-duct heat exchanger. The variation of $\mathrm{Nu}$ with $\mathrm{Re}$ for the baffle insert is depicted in Fig. 4a. It can be observed in the figure that the values of $\mathrm{Nu}$ are found to increase with the increment of Re and BR. The heat transfer in the baffled duct shows the considerable increase above that in the flat duct alone. It is worth noting that the use of largest BR provides the maximum $\mathrm{Nu}$ value. In the current work, the $\mathrm{Nu}$ values are, respectively, around $64.2 \%, 72.4 \%, 75.7 \%$, $76.4 \%$ and $77.5 \%$ above the smooth/flat duct for using $\mathrm{BR}=0.1,0.2,0.3,0.4$ and 0.5 .

The variation of the ratio of $\mathrm{Nu}$ in the baffled duct to $\mathrm{Nu}$ in the flat duct $\left(\mathrm{Nu} / \mathrm{Nu}_{0}\right)$ with $\mathrm{Re}$ is portrayed in Fig. 4b. It is seen in the figure that $\mathrm{Nu} / \mathrm{Nu}_{0}$ decreases slightly with increasing Re while increases with the rise in $\mathrm{BR}$. The $\mathrm{Nu} / \mathrm{Nu}_{0}$ has a maximum for $\mathrm{BR}=0.5$. This is caused by stronger vortexflow strength of larger BR, increasing turbulence intensity and rapid fluid mixing apart from more interrupting the boundary layer, resulting in the fantastic increase in heat transfer. 


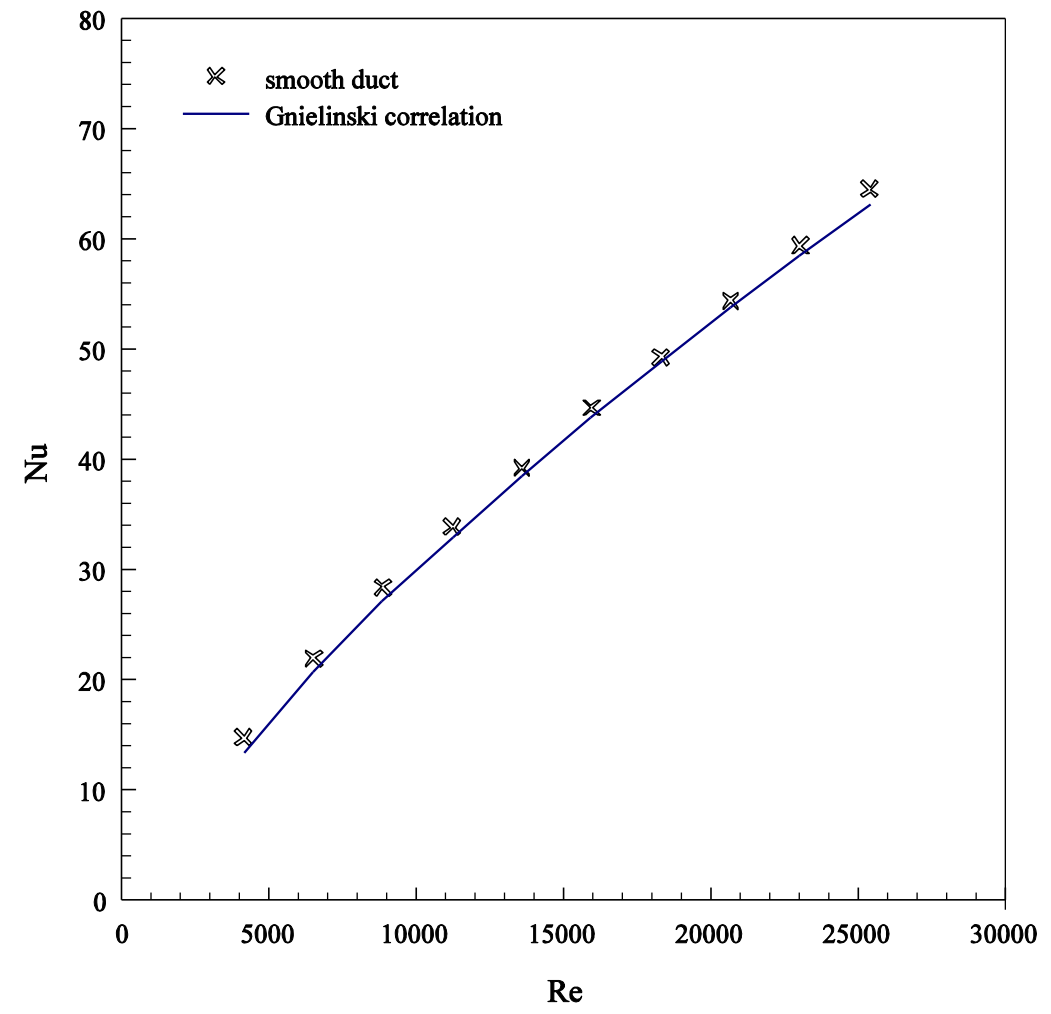

(a)

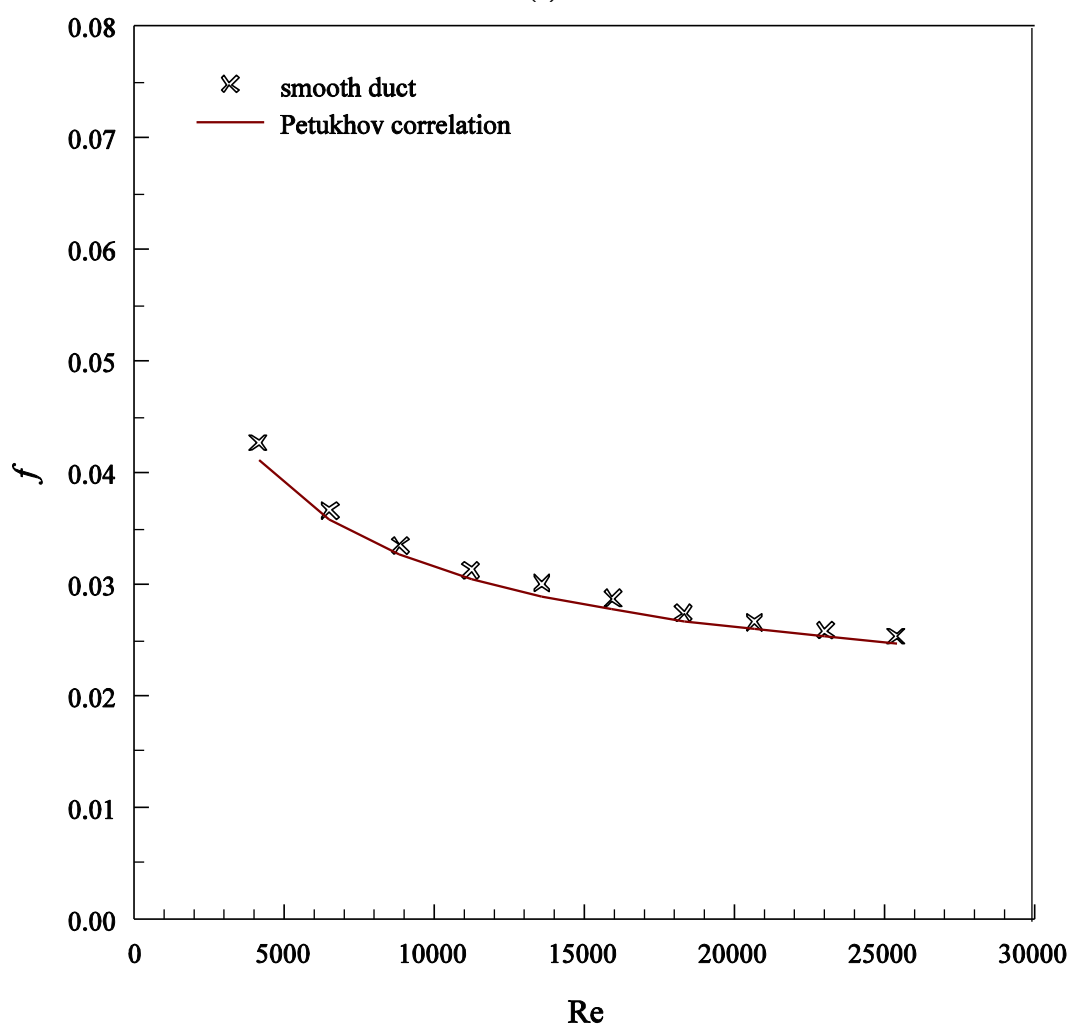

(b)

Fig. 3. Verification of (a) $\mathrm{Nu}$ and (b) $f$ for smooth duct. 


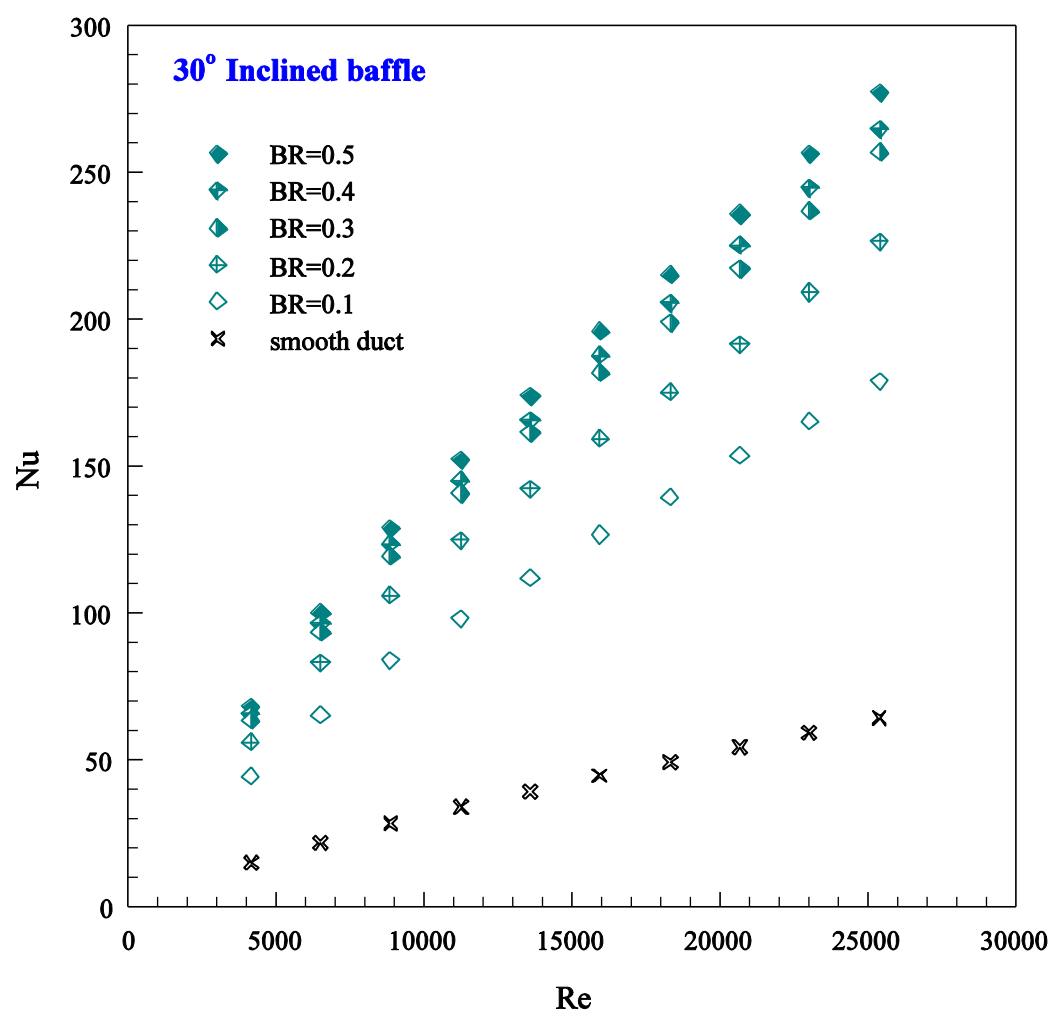

(a)

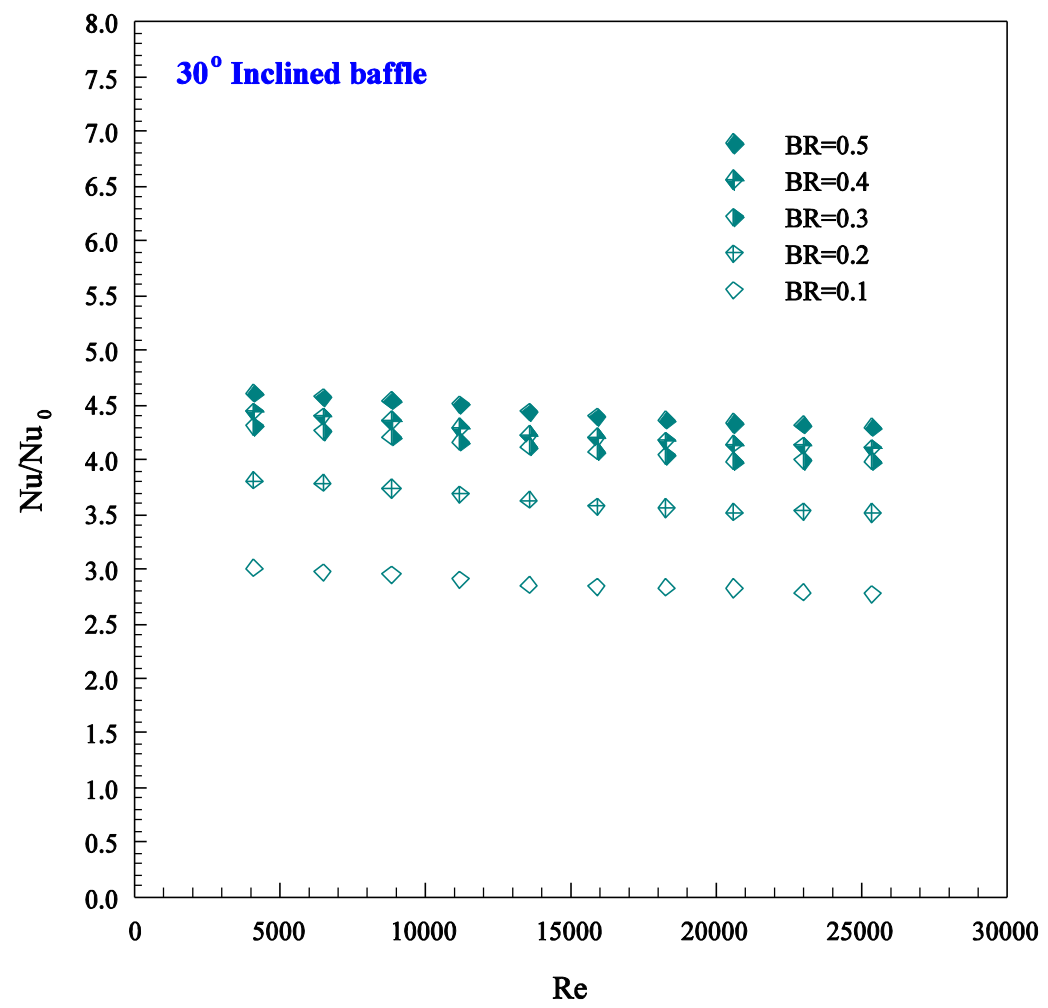

(b) 


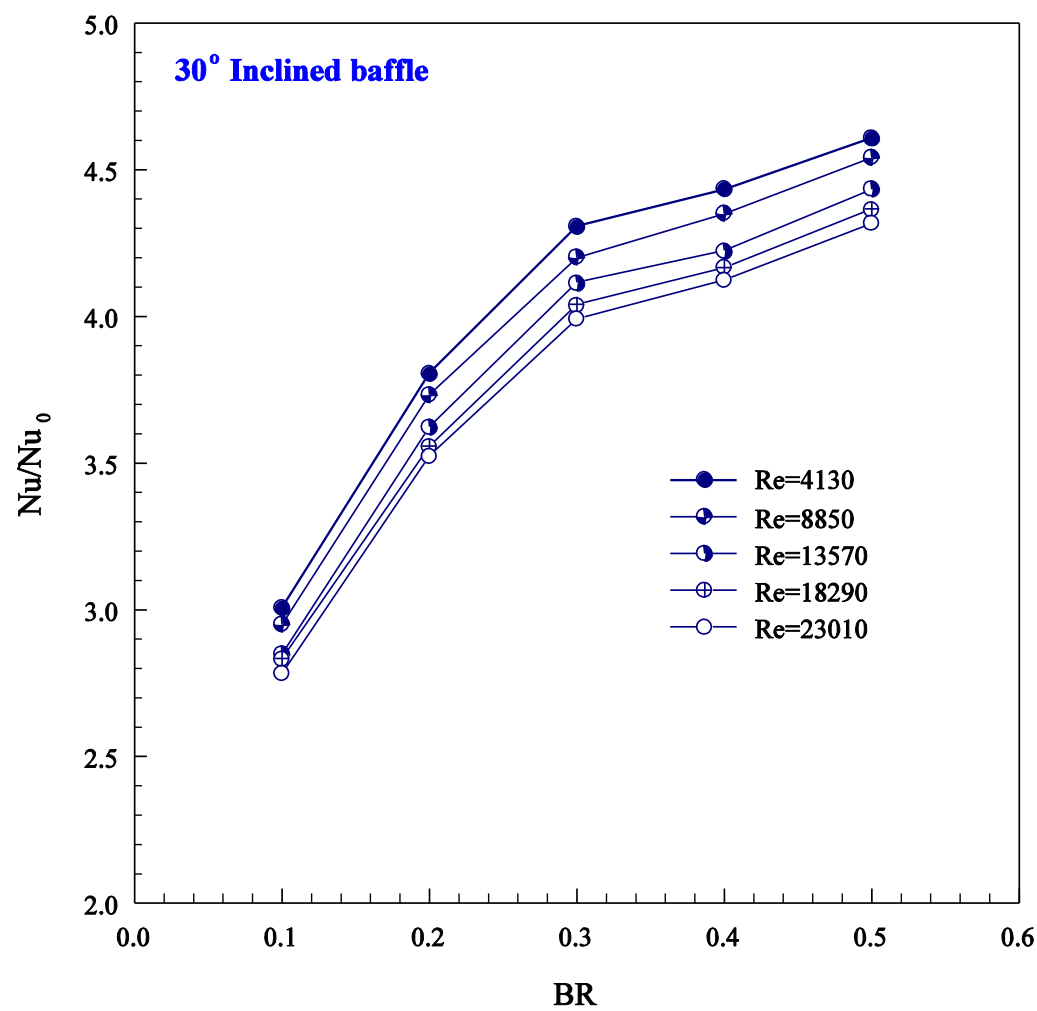

(c)

Fig. 4. (a) $\mathrm{Nu}$ versus $\mathrm{Re}$, (b) $\mathrm{Nu} / \mathrm{Nu}_{0}$ versus $\mathrm{Re}$ and (c) $\mathrm{Nu} / \mathrm{Nu}_{0}$ versus $\mathrm{BR}$.

Figure $4 \mathrm{c}$ displays the $\mathrm{Nu} / \mathrm{Nu}_{0}$ variation with $\mathrm{BR}$ for different Re values. It is seen in Fig. $4 \mathrm{c}$ that $\mathrm{Nu} / \mathrm{Nu}_{0}$ tends to rise steeply at the beginning with increasing BR. The $\mathrm{Nu} / \mathrm{Nu}_{0}$ shows the rapidly increasing trend with the increment of BR from 0.1 to 0.3 and then displays a gradual increase for BR $>0.3$. $\mathrm{The} \mathrm{Nu} / \mathrm{Nu}_{0}$ values are, respectively, in the range of 4.3-4.6, 4.1-4.4, 3.9-4.3, 3.5-3.8 and 2.8-3.0 for $\mathrm{BR}=0.5,0.4,0.30 .2$ and 0.1 depending on Re values. The $\mathrm{BR}=0.5$ provides, respectively, the average $\mathrm{Nu} / \mathrm{Nu}_{0}$ around $4.4,7.3,18.2$ and $35.2 \%$ above the $\mathrm{BR}=0.4,0.3,0.2$ and 0.1 .

\subsection{Friction Loss Results}

The relations of $f$ and $f / f_{0}$ with Re for various BR values are, respectively, shown in Fig. $5 \mathrm{a}$ and $\mathrm{b}$ while the profile of $f / f_{0}$ with BR is depicted in Fig. 5c. It can be observed in Fig. 5a that using the baffle insert results in an extreme increase in $f$ above the flat duct. The $\mathrm{BR}=0.5$ gives the average increase in $f$ at about $41.1 \%$, $57.6 \%, 64.4 \%$ and $74.6 \%$ higher than the $\mathrm{BR}=0.4,0.3,0.2$ and 0.1 , respectively. This very high friction loss is due to the presence of the baffles creating more obstruction in the development of the boundary layer of flow. Moreover, this can be explained from the fact of higher flow blockage due to the baffle, larger area of the surface and the reversing flow. The $f / f_{0}$ of the largest BR shows the maximum value as can be seen in Fig. 5b.

Figure $5 \mathrm{c}$ shows the effect of BR on $f / f_{0}$ for different Re values. It is noted in the figure that $f / f_{0}$ shows the gradual increase with the increment of $\mathrm{BR}$ until $\mathrm{BR}=0.3$ and then displays the rapid increase for $\mathrm{BR}>$ 0.3 . Among the $\mathrm{BR}$ values, the $\mathrm{BR}=0.5$ yields the highest $f / f_{0}$. The $\mathrm{BR}=0.5,0.4,0.3,0.2$ and 0.1 provide the average $f / f_{0}$ values around 54.0, 31.7, 22.8, 19.1 and 13.7 times, respectively. 


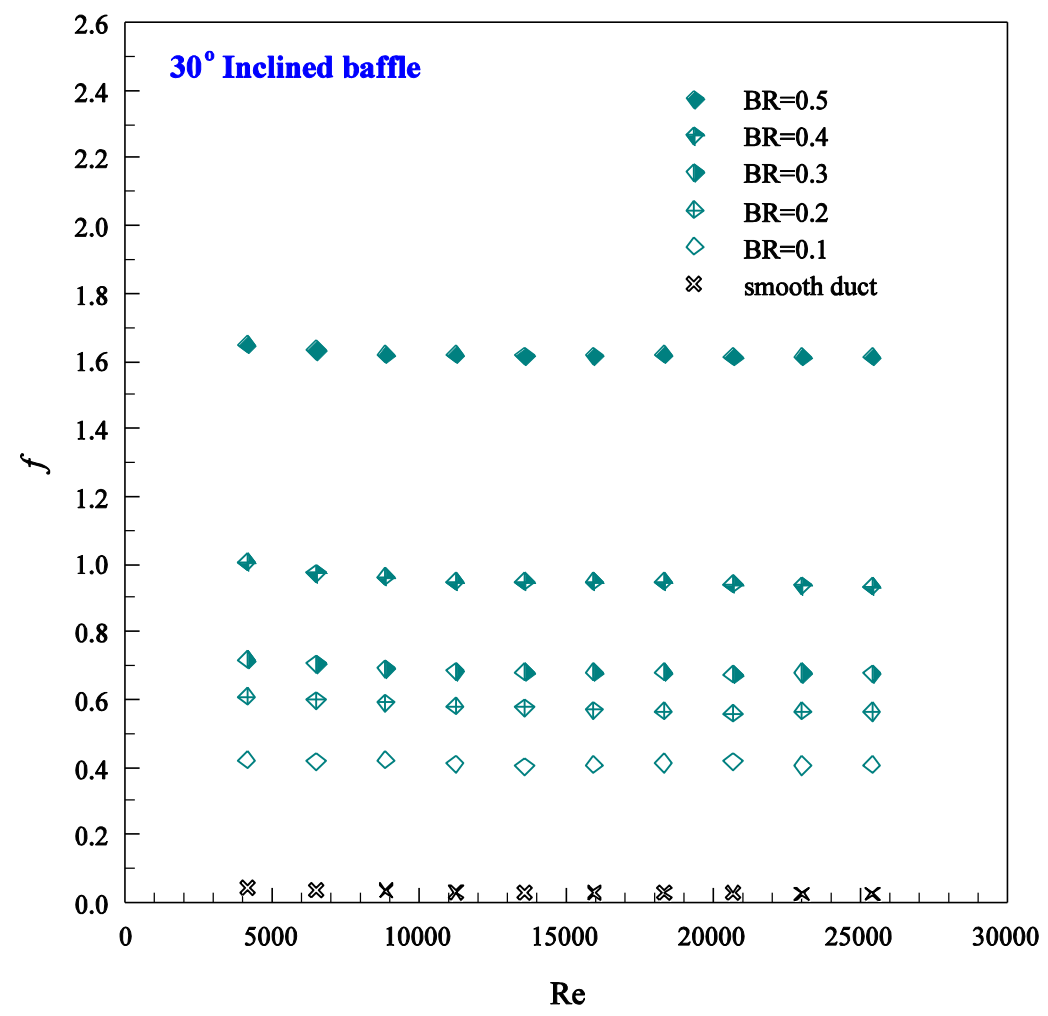

(a)

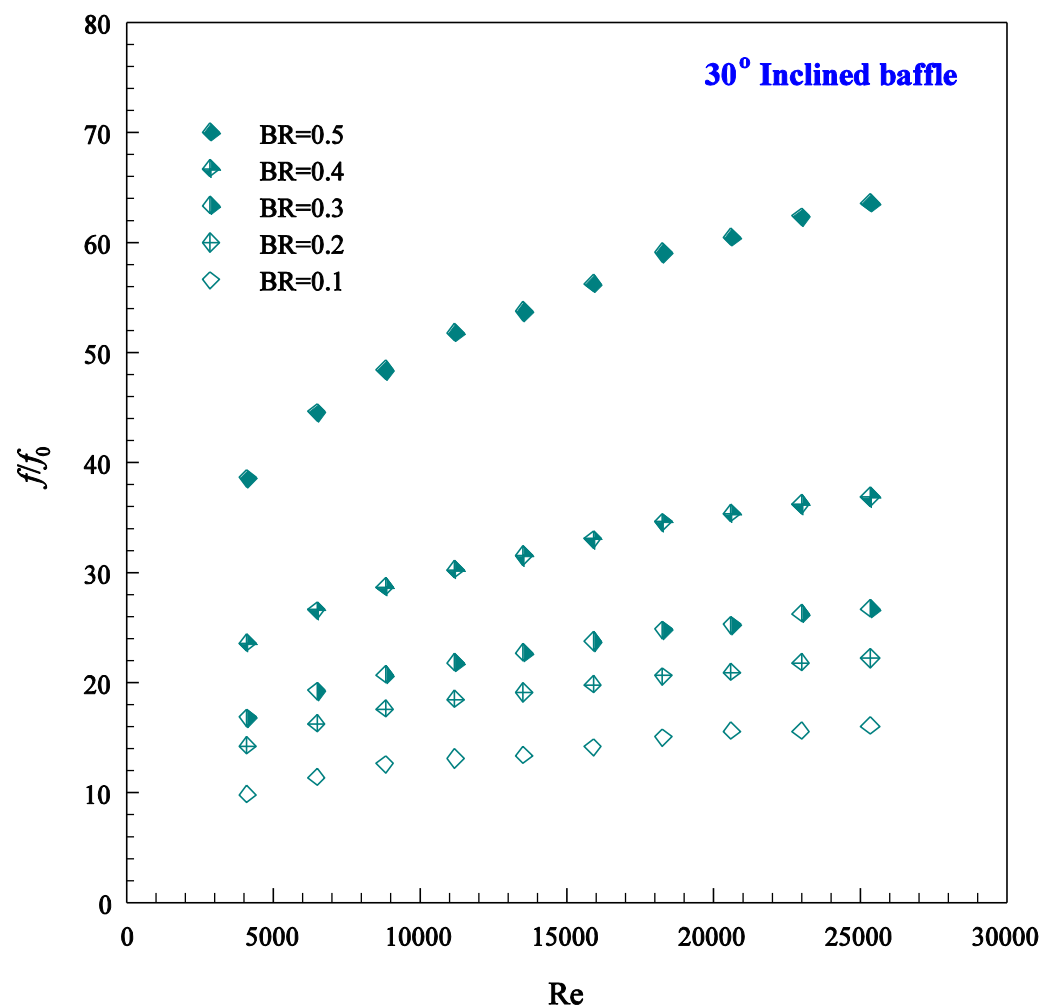

(b) 


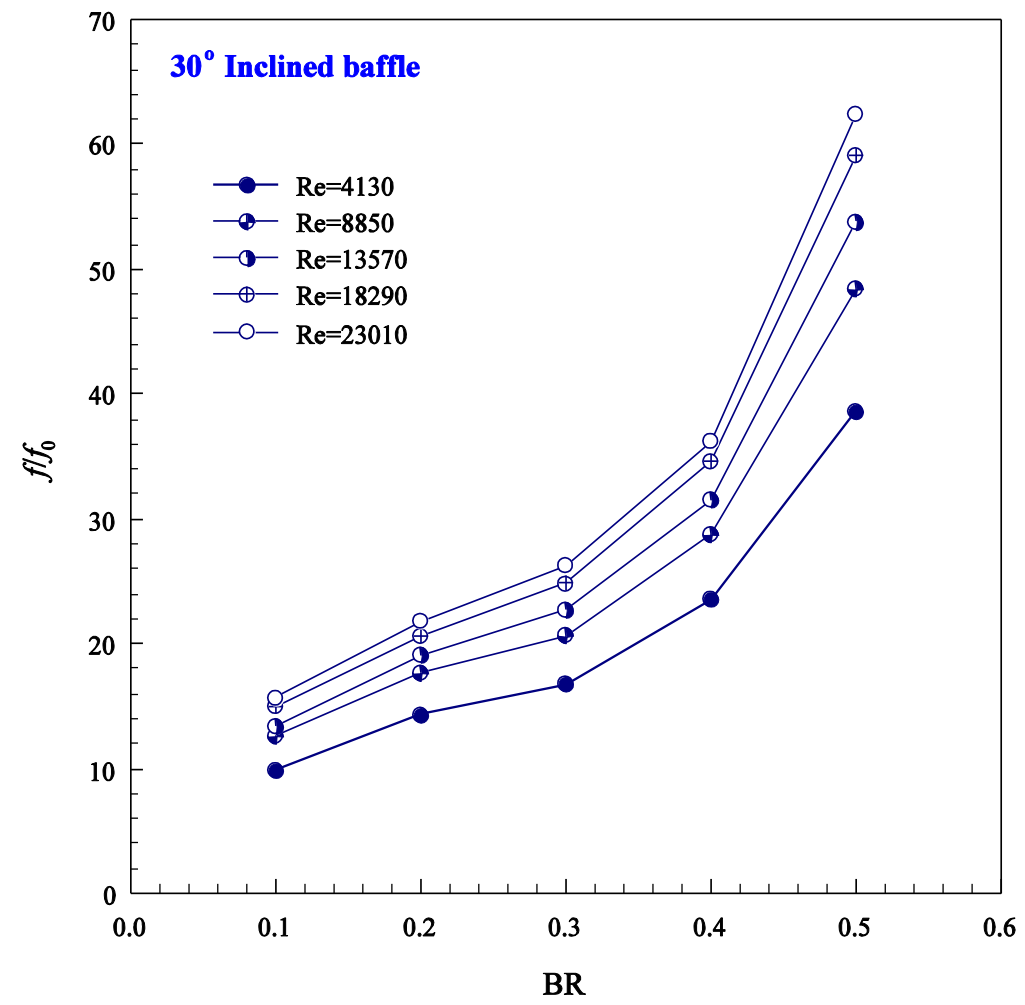

(c)

Fig. 5. (a) $f$ against $\operatorname{Re},(b) f / f_{0}$ against Re, and (c) $f / f_{0}$ against BR.

\subsection{Thermal Performance Results}

The relationship between thermal enhancement factor $(\eta)$ at similar pumping power and Re is presented in Fig. 6. In the figure, $\eta$ tends to reduce with the rise of Re for all BRs. Determining from Eq. (8), the $\eta$ of the inclined baffle at $\mathrm{BR}=0.3$ is highest around 1.68 at the lowest Re. The maximum $\eta$ are, respectively, about $1.40,1.57,1.68,1.55$ and 1.36 for $\mathrm{BR}=0.1,0.2,0.3,0.4$ and 0.5 . The $\mathrm{BR}=0.3$ yields the $\eta$ around 6 $7 \%, 8-9 \%, 16-17 \%$ and $18-19 \%$ higher than the $\mathrm{BR}=0.2,0.4,0.1$ and 0.5 , respectively. This can be concluded that to achieve higher thermal performance, the baffle with $\mathrm{BR}=0.3, \alpha=30^{\circ}$ should be employed. 


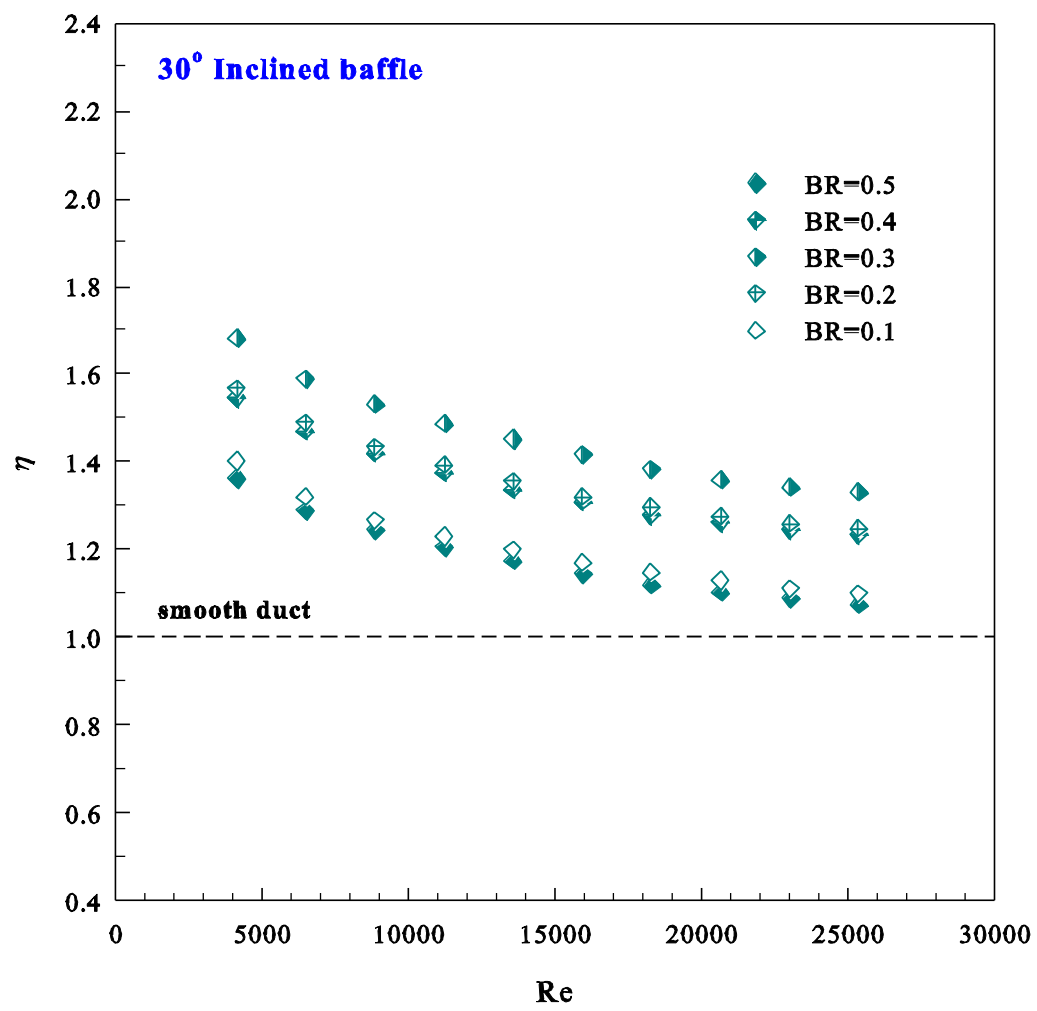

Fig. 6. Variation of $\eta$ with Re for various BRs.

\section{Conclusions}

The effects of the inclined baffles with different blockage ratios, $\mathrm{BR}(=0.1,0.2,0.3,0.4$ and 0.5$)$ on the heat transfer, friction factor and thermal performance behaviors have been investigated experimentally for Re from 4100 to 25,600 . The findings from the results can be concluded as:

1. Nu tends to increase with the rise of $\mathrm{Re}$ but $\mathrm{Nu} / \mathrm{Nu}_{0}$ shows nearly free from Re.

2. The increases in BR and Re provide higher heat transfer rate and friction loss.

3. The highest $\mathrm{Nu} / \mathrm{Nu}_{0}$ of 4.6 and $f / f_{0}$ of 63.67 is found for $\mathrm{BR}=0.5$.

4. $\eta$ shows the downtrend with increasing Re and the baffles with $\mathrm{BR}=0.1,0.2,0.3,0.4$ and 0.5 give the highest $\eta$ around 1.40,1.57, 1.68, 1.55 and 1.36, respectively.

5. The $\mathrm{BR}=0.3$ baffle yields the highest $\eta$.

\section{References}

[1] S. Eiamsa-ard, K. Wongcharee, and P. Promvonge, "Experimental investigation on energy separation in a counter-flow Ranque-Hilsch vortex tube: Effect of cooling a hot tube," Int. Commun. Heat Mass Transf., vol. 37, pp. 156-162, 2010.

[2] P. Promvonge, "Heat transfer and pressure drop in a channel with multiple $60^{\circ}$ V-baffles," Int. Commun. Heat Mass Transf., vol. 37, pp. 835-840, 2010.

[3] S. Skullong, P. Promvonge, C. Thianpong, and M. Pimsarn, "Thermal performance in solar air heater channel with combined wavy-groove and perforated-delta wing vortex generators," Appl. Therm. Eng., vol. 100, pp. 611-620, 2016.

[4] S. Skullong, P. Promvonge, C. Thianpong, N. Jayranaiwachira, and M. Pimsarn, "Heat transfer augmentation in a solar air heater channel with combined winglets and wavy grooves on absorber plate," Appl. Therm. Eng., vol. 122, pp. 268-284, 2017.

[5] P. Promvonge, "Thermal enhancement in a round tube with snail entry and coiled-wire inserts," Int. Commun. Heat Mass Transf., vol. 35, pp. 623-629, 2008. 
[6] S. Skullong, P. Promvonge, C. Thianpong, and M. Pimsarn, "Heat transfer and turbulent flow friction in a round tube with staggered-winglet perforated-tapes," Int. J. Heat Mass Transf., vol. 95, pp. 230-242, 2016.

[7] S. Tamna, Y. Kaewkohkiat, S. Skullong, and P. Promvonge, "Heat transfer enhancement in tubular heat exchanger with double V-ribbed twisted-tapes," Case Stud. Therm. Eng., vol. 7, pp. 14-24, 2016.

[8] P. Sivashanmugam and S. Suresh, "Experimental studies on heat transfer and friction factor characteristics of turbulent flow through a circular tube fitted with helical screw-tape inserts," Chem. Eng. Process. Process Intensif., vol. 46, no. 12, pp. 1292-1298, 2007.

[9] P. Promvonge and S. Eiamsa-ard, "Heat transfer and turbulent flow friction in a circular tube fitted with conical-nozzle turbulators," Int. Commun. Heat Mass Transf., vol. 34, pp. 72-82, 2007.

[10] F. Kreith and D. Margolis, "Heat transfer and friction in turbulent vortex flow," Appl. Sci. Res., vol. 8, pp. 457-473, 1959.

[11] P. Promvongen and S. Eiamsa-ard, "Heat transfer in a circular tube fitted with free-spacing snail entry and conical-nozzle turbulators," Int. Commun. Heat Mass Transf., vol. 34, pp. 838-848, 2007.

[12] P. Promvonge, S. Pethkool, M. Pimsarn, and C. Thianpong, "Heat transfer augmentation in a helicalribbed tube with double twisted tape inserts," Int. Commun. Heat Mass Transf., vol. 39, pp. 953-959, 2012.

[13] S. W. Chang, Y. J. Jan, and J. S. Liou, "Turbulent heat transfer and pressure drop in tube fitted with serrated twisted-tape," Int. J. Therm. Sci., vol. 46, pp. 506-518, 2007.

[14] S. Eiamsa-ard, C. Thianpong, and P. Promvonge, "Experimental investigation of heat transfer and flow friction in a circular tube fitted with regularly spaced twisted tape elements," Int. Commun. Heat Mass Transf., vol. 33, no. 10, pp. 1225-1233, 2006.

[15] P. Promvonge and S. Eiamsa-ard, "Heat transfer enhancement in a tube with combined conicalnozzle inserts and swirl generator," Energy Convers. Manage., vol. 47, no. 18-19, pp. 2867-82, 2006.

[16] P. Promvonge and S. Eiamsa-ard, "Heat transfer behaviors in a tube with combined conical-ring and twisted-tape insert," Int. Commun. Heat Mass Transf., vol. 34, no. 7, pp. 849-59, 2007.

[17] P. Promvonge and S. Eiamsa-ard, "Heat transfer augmentation in a circular tube using V-nozzle turbulator inserts and snail entry," Exp. Therm. Fluid Sci., vol. 32, no. 1, pp. 332-40, 2007.

[18] K. H. Ko and N. K. Anand, "Use of porous baffles to enhance heat transfer in a rectangular channel," International Journal of Heat and Mass Transfer, vol. 46, pp. 4191-4199, 2003.

[19] C. Berner, F. Durst, and D. M. McEligot, "Flow around baffles," ASME J. Heat Transf., vol. 106, pp. 743-749, 1984.

[20] A. Gupta, V. SriHarsha, S. V. Prabhu, and R. P. Vedula, "Local heat transfer distribution in a square channel with $90^{\circ}$ continuous, $90^{\circ}$ saw tooth profiled and $60^{\circ}$ broken ribs," Exp. Therm. Fluid Sci., vol. 32, pp. 997-1010, 2008.

[21] P. Promvonge, S. Skullong, S. Kwankaomeng, and C. Thianpong, "Heat transfer in square duct fitted diagonally with angle-finned tape-Part 1: Experimental study," Int. Commun. Heat Mass Transf., vol. 39, pp. 617-624, 2012.

[22] P. Promvonge, S. Skullong, S. Kwankaomeng, and C. Thianpong, "Heat transfer in square duct fitted diagonally with angle-finned tape-Part 2: Numerical study," Int. Commun. Heat Mass Transf., vol.3 9, pp. 625-633, 2012.

[23] S. Skullong, C. Thianpong, N. Jayranaiwachira, and P. Promvonge, "Experimental and numerical heat transfer investigation in turbulent square-duct flow through oblique horseshoe baffles," Chem. Eng. Process. Process Intensif., vol. 99, pp. 58-71, 2016.

[24] R. L. Webb, "Performance evaluation criteria for use of enhanced heat transfer surfaces in heat exchanger design," Int. J. Heat Mass Transf., vol. 24, pp. 715-726, 1981.

[25] F. P. Incropera, P. D. Dewitt, T. L. Bergman, and A. S. Lavine, Foundations of Heat Transfer, 6th ed. John-Wiley \& Sons, 2012. 